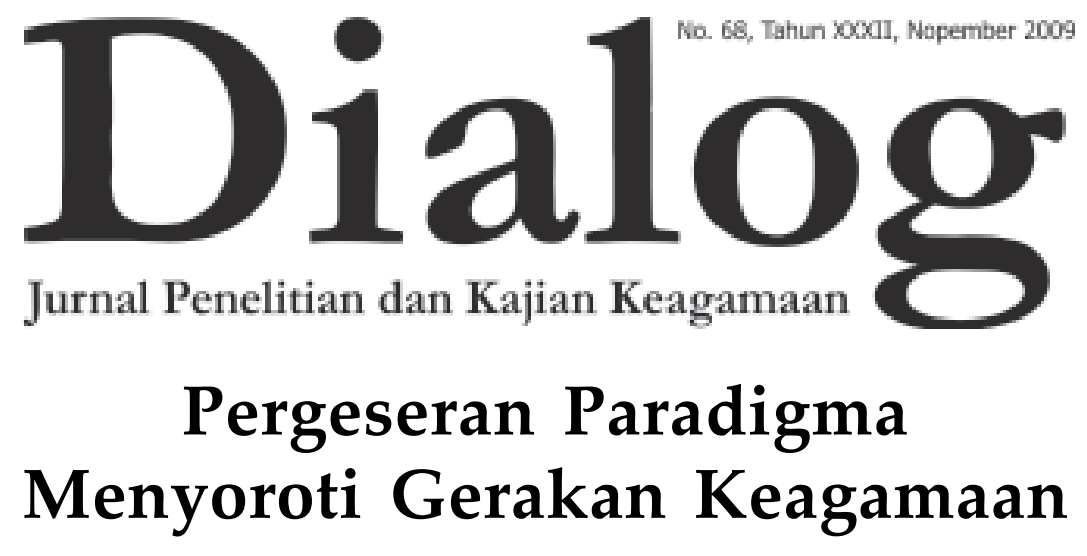




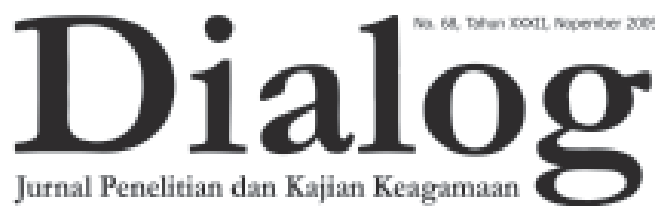

Pemi mpin Umum:

Prof. Dr. H. M. Atho Mudzhar, MA

Redaktur Ahli:

Prof. Dr. H. Nasaruddin Umar, MA

Prof. Dr. H. Komarudin Hidayat, MA

Pemimpin Redaksi / Penanggung J awab

Drs. H. Syamsuddin

Wakil Pemi mpin Redaksi

H. Fanani Suprianto, SH., MM

Sekretaris Redaksi

M. Rosyid Fauzi, S.Si.

Dewan Redaksı

Prof. Dr. H. Abdurrahman Mas'ud Drs. Amin Haedari

Prof. Dr. H. Maidir Harun

Drs. H. Mohammad Shohib, MA

Drs. H. Asmu'i, SH, MM

Chamdi Pamudji, SH., MM

Redaktur Eksekutif

M. Nasir, S.Th.I.

Redaktur Pelaksana

Moh. Rosyid Fauzi, S.Si

M. Nasir, S.Th.I

M. Adlin Sila, M.A

Abbas Jauhari, M.Ag

Administrasi

Drs. Dedy Curipno

Sutidjah

Desriyanti Nasution, S.IPI

Drs. H. Sahlani

Alamat Redaksi

Gedung Bayt Alquran Museum Istiqlal Komplek Taman Mini Indonesia Indah

Telp. (021) 87791444-87794982

Website:

www. balitbangdiklat.depag.go.id

Email:

info@depag.web.id

\section{Pergeseran Paradigma Menyoroti Gerakan Keagamaan}

Fenomena munculnya berbagai aliran keagamaan di Indonesia beberapa tahun terakhir menunjukan kecenderungan positif dalam kebebasan beragama. Namun sayangnya kebebasan menampilkan ekspresi keberagamaan tersebut kerapkali melampaui dari apa yang semestinya. Hal tersebut dapat kita lihat dengan munculnya gerakan keagamaan yang mengusung berbagai macam ajaran, ritual keagamaan yang aneh bahkan cenderung mengancam serta menodai kesucian aqidah, ibadah, ritual, dan pendirian mayoritas ummat yang sudah mapan. Sejak tahun 1989, setidaknya telah ada beberapa aliran keagamaan diberikan label haram oleh MUI (Majelis Ulama Indonesia), diantara aliran yang dianggap menyesatkan itu antara lain: Islam Jama'ah, Ahmadiyah, Ingkar Sunnah, Qur'an Suci, Sholat Dua Bahasa, Lia Eden dan al-Qiyadah al-Islamiyah.

Fenomena ini ditenggarai oleh sebagian pihak sebagai akibat dari kegagalan dakwah. Para da'i dianggap tidak mampu mentransformasikan nilainilai ajaran Islam secara kaffah 
(komprehensif) kepada ummat, dakwah selama ini sering bersifat eksklusif, menghakimi dan memprovokasi. Aktifitas dakwah hanya menampilkan Islam dari aspek langit atau 'ubudiyah (habluminallah) bukan aspek bumi dimana kehidupan sosial (habluminannas) bergulir, sehingga wajar berbagai permasalahan sosial yang dialami ummat tidak tersentuh. Fakta ini menyebabkan ummat mencari solusi lain atas permasalahan sosial yang mereka alami dengan cara "selingkuh" yaitu menganut sekte atau aliran baru dalam sebuah agama yang menawarkan solusi instan, namun cenderung "menyesatkan".

Para da'i, tokoh masyarakat, maupun para pemegang kebijakan ke depan harus mampu merubah paradigma yang selama ini salah dan telah mengkristal di kalangan ummat. Mereka diharapkan tidak berperan sebagai juru dakwah, juru vonis, juru putus, yang hanya menyampaikan pesan bil lisan di atas mimbar saja, tapi lebih dari itu, merek dituntut menjadi -meminjam istilah Clifford Geertz- cultural broker (makelar budaya), bahkan menjadi intermediary forces (kekuatan perantara) bagi permasalahan sosial ummat dalam istilah Hiroko Horikoshi.

Dalam kajian Jurnal Dialog Edisi ini mencoba mengulas tentang Pergeseran Paradigma Menyoroti Gerakan Keagamaan yang kerapkali menghadirkan tematema aktual di tengah-tengah masyarakat. Kajian Jurnal Dialog edisi ini diawali dengan tulisan Prof. Dr. H.M.
Atho Mudzhar tentang Instrumen Internasional dan Peraturan Perundangan Indonesia tentang Kebebasan dan Perlindungan Beragama. Dilanjutkan dengan tulisan Prof. Dr. Abdurrahman Mas'ud yang mengupas tentang Menyikapi Keberadaan Aliran Sempalan.

Sukris Sarmadi, Dosen STAIN Banjarmasin menghadirkan tulisan tentang Transformasi NU dalam Masyarakat Banjar Kini PerspektifPergeseran Gerakan Keagamaan di Kalimantan Selatan. Sedangkan M. Ulinnuha Khusnan, MA melalui tulisannya mencoba memotret Paradigma Keberagamaan Kaum Santri. Nurhasanah dosen UIN Jakarta menghadirkan tulisan tentang Politik Kebijakan Islamisasi Mahathir. Kajian jurnal dialog edisi ini kian lengkap dengan hadirnya tulisan Anwar Mujahidin, MA, tentang Science And Religion (Paradigma Al-Qur'an untuk IlmuIlmu Sosial Menurut Pemikiran Kuntowijoyo).

Di samping memuat artikel ilmiah, Jurnal Dialog edisi ini juga memuat laporan hasil penelitian oleh Ridwan Bustaman, tentang Analisis Wacana Kritis : Tayangan Kekerasan dalam Sinetron Bernuansa Keagamaan. Dan juga hasil penelitian saudara Basuki tentang Pesantren, Tasawufdan Hedonisme Kultural (Studi Kasus Aktualisasi Nilai-nilai Tasawuf dalam Hidup dan Kehidupan di Pondok Pesantren Modern Gontor). Serta hasil penelitian saudari Maryam tentang Interaksi Sosial Pelaku Konversi Agama Etnik Cina.

Kajian ini diakhiri dengan telaah 
buku yang mengulas buku karya Prof. Abdurrahman, 2009 yang berjudul Menebar Rahmat bagi Sekalian Alam. Semoga kajian yang dihadirkan Jurnal Dialog edisi ini memberikan manfaat yang berarti bagi para pembaca, khususnya dalam kajian Pergeseran Paradigma Menyoroti Gerakan Keagamaan. Selamat Membaca!

Redaksi

4 Dialog No. 68, Tahun XXXII, Nopember 2009 
TOPIK

M. Atho Mudzhar

Instrumen Internasional dan Peraturan Perundangan Indonesia tentang Kebebasan dan Perlindungan Beragama - -6

Abdurrahman Mas'ud

Menyikapi Keberadaan Aliran Sempalan --16

SUKRIS SARMADI

Transformasi NU dalam Masyarakat Banjar Kini Perspektif Pergeseran Gerakan Keagamaan di Kalimantan Selatan - 25

\section{Ulinnuha KhuSNAN}

Memotret Paradigma Keberagamaan Kaum Santri —41

\section{NuRHASANAH}

Politik Kebijakan Islamisasi Mahathir —65

\section{Anwar Mujahidin}

Science And Religion (Paradigma Al-Qur'An untuk Ilmu-Ilmu Sosial Menurut Pemikiran Kuntowijoyo) -78

\section{PENELITIAN}

\section{RidWAN Bustamam}

Analisis Wacana Kritis : Tayangan Kekerasan dalam Sinetron Bernuansa Keagamaan $\longrightarrow 97$

\section{BASUKI}

Pesantren, Tasawuf dan Hedonisme Kultural (Studi Kasus Aktualisasi Nilainilai Tasawuf dalam Hidup dan Kehidupan di Pondok Pesantren Modern Gontor) -112

MARYAM

Interaksi Sosial Pelaku Konversi Agama Etnik Cina --135

\section{BOOK REVIEW}

\section{Dewi $\mathbf{N}$}

Menebar Rahmat bagi Sekalian Alam —149 


\title{
Politik Kebijakan Islamisasi Mahathir
}

\author{
OLEH : NURHASANAH
}

\begin{abstract}
:
Mahathir leadership era has been marked by his larger and substantive interest to carry Islam on the goverment policy and various programs. It is said that Islamization policy which Mahathir speed up basically does not only spring from goverment intrinsic impetus to promote Islam, but also external political pressures. This article discusses the mount of Islamization policy in Malaysia, especially in Mahathir era; and poins out the conditions that underly his policy
\end{abstract}

Kebijakan Islamisasi Malaysia mulai mencuat pada masa kepemimpinan Tun Abdul Razak, meskipun dinilai bersifat simbolis dan politis, di mana Mahathir terlibat di dalamnya sebagai Menteri Pengajaran dan Menteri Perindustrian dan Perdagangan. Mahathir di situ mempunyai peran penting dalam mendorong lahirnya kebijakankebijakan Islam, baik pada masa pemerintahan Tun Abdul Razak (19711976) maupun Tun Hussein Onn (19761981). Namun, kecenderungan Mahathir terhadap Islam semakin menguat ketika ia diangkat menjadi Perdana Menteri menggantikan Tun Hussein Onn yang mundur karena kesehatannya yang memburuk. ${ }^{1}$

*) Nurhasanah adalah dosen Fakultas Syariah dan Hukum UIN Jakarta.

${ }^{1}$ A. Effendy Choirie, Islam dan Nasionalisme: Kajian Perbandingan Mengenai Perjuangan Politik UMNO (Malaysia) dan PKB (Indonesia) [Tesis pada Jabatan Antropologi dan Sosiologi Fakulti Sastera dan Sains Sosial, Universiti Malaya, Kuala Lumpur, 2007) h. 197.
Kebijakan Islamisasi yang dilancarkan Mahathir pada dasarnya tidak lahir dari dorongan intrinsik pemerintah untuk mempromosikan Islam semata, melainkan juga karena adanya tekanan-tekanan politik eksternal. Tekanan tersebut datang dari serbuan gelombang kebangkitan Islam dan meningkatnya tantangan PAS kekuatan oposisi utama yang mengibarkan bendera Islam. Untuk merespon dua tantangan tersebut, pada tahun 1980-an, UMNO dan pemerintah mengkampanyekan wacana 'Islam yang benar' (right Islam) untuk dikontraskan dengan praktek Islam yang salah (wrong Islam). Promosi tentang right Islam itu didasarkan pada gagasan bahwa Islam adalah agama progresif yang selaras dengan upaya-upaya pemerintah menggalakkan pembangunan dan modernisasi. Oleh karena itu, visi tentang right Islam ditegaskan sebagai " $a$ balanced, moderate and modernising force" 
yang tidak merintangi investasi asing; menerima bentuk-bentuk tertentu dari Barat sekular; serta memberikan perhatian pada realitas politik dunia Islam kekinian dan dunia 1uar. ${ }^{2}$

Gerakan Islam yang menentang visi Islam pemerintah itu dicap sebagai penyeleweng, ekstremis, dan radikal. Cap-cap tersebut dialamatkan kepada mereka yang dianggap mengganggu kesatuan persepsi mengenai Islam yang hendak didefinisikan pemerintah, yakni Islam yang cocok dengan agenda pembangunan dan modernisasi Malaysia. Singkatnya, program-program Islamisasi pemerintah yang dilancarkan pada akhir 1970-an tidak bisa dilepaskan dari motif-motif yang bersifat politik. Menurut pengamatan Mutalib, ada dua alasan utama yang melatarbelakangi kebijakan Islamisasi pemerintah. Pertama, keinginan untuk mengecoh PAS dan melihat seberapa jauh daya tarik PAS terhadap bangsa Melayu; dan kedua, keinginan untuk mengatur kegiatan-kegiatan Islam di Malaysia agar tidak memperburuk stabilitas antaretnis. $^{3}$

Alasan pertama terungkap dari pernyataan terbuka pemerintah sebagaimana dilaporkan Far Eastern Economic Review (9 Februari 1979)bahwa alasan pokok bagi programprogram Islamisasinya adalah untuk mengecoh PAS. ${ }^{4}$ Dalam situasi di mana kebangkitan Islam tengah dibicarakan secara luas, termasuk di lingkungan elitelit Melayu UMNO, tidak ada alternatif lain kecuali menghadapi arus Islam dengan melaksanakan banyak program Islamisasi. Abrahim Ahmad

\footnotetext{
${ }^{2}$ Choirie, Islam dan Nasionalisme, h. 186.

${ }^{3}$ Hussin Mutalib, Islam dan Etnisitas Perspektif Politik Melayu (Jakarta: LP3ES, 1996), h. 211.

${ }^{4}$ Mutalib, Islam dan Etnisitas, h. 211.
}

menyebutnya: "to challenge Islam with more Islam". ${ }^{5}$

Alasan kedua terkait dengan kesadaran pemerintah akan potensi politik Islam yang harus diatur atau dipandu agar tidak menjadi sumber ketidakstabilan hubungan anteretnis. ${ }^{6}$ Pemerintah yang menjadi tulang punggung UMNO menerapkan dua jenis strategi, yaitu akomodasi - untuk tidak mengatakan kooptasi-, dan represi. Strategi pertama dijalankan lewat rekrutmen tokoh-tokoh organisasi Islam terkemuka ke dalam pemerintahan. Contoh strategi ini adalah rekrutmen ${ }^{7}$ Anwar Ibrahim ke dalam UMNO pada 1982 yang dipandang banyak pihak sebagai keberhasilan UMNO memobilisasi citra sebagai partai yang memperjuangkan Islam. Bergabungnya Anwar ke dalam UMNO mencerminkan kesungguhan partai itu menerapkan Islam dalam negara. ${ }^{8}$

Ketika strategi pertama tidak membuahkan hasil cukup efektif, pemerintah menerapkan strategi represi dengan mengambil langkah-langkah yang sifatnya menghukum dalam rangka mengekang meningkatnya

${ }^{5}$ Ibrahim Ahmad, Konflik UMNO-PAS dalam Isu Islamisasi (Selangor: lbs Buku Sdn. Bhd., 1989), hal. 69.

${ }^{6}$ Mutalib, Islam dan Etnisitas, h. 212.

${ }^{7}$ Bagi Milne dan Mauzy, ini merupakan kooptasi. Lihat R.S. Milne dan Diane K. Mauzy, Malaysian Politics under Mahathir (London and New York: Routledge, 1999), h. 85.

${ }^{8}$ Choirie, Islam dan Nasionalisme, h. 198; lihat pula Sudarnoto Abdul Hakim, Orientasi dan Dinamika Sosial Politik Angkatan Belia Islam Malaysia [ABIM] (Disertasi Program Pascasarjana Universitas Islam Negeri Syarif Hidayatullah Jakarta, 2006), h. 240.

'Simon Barraclough, "Managing the Challenges of the Islamic Revival in Malaysia: A Regime Perspective". Dalam Asian Survey, Vol. 19, No. 4 (1985), hal. 15-20. 
aktivitas dari kelompok-kelompok yang disebut sebagai 'penyeleweng', 'radikal', dan 'ekstremis'. Strategi ini diwujudkan melalui pemberlakuan Akta Hasutan (1970), Akta Keamanan Dalam Negeri (revisi 1972), dan Akta Kemasyarakatan (1981). Langkah-langkah ini diambil pemerintah guna mengancam, mengendalikan; bahkan melakukan penentangan secara diam-diam terhadap PAS dan warga Muslim lain yang pendapatnya berbeda dengan pemerintah. ${ }^{9}$ Untuk membatasi penyebaran doktrin-doktrin yang dianggap menyimpang, pemerintah juga menerapkan Akta Salah Ugama 1982. Dengan Akta ini, setiap warga Muslim dilarang berbicara tentang ajaran-ajaran Islam yang dapat menimbulkan keresahan masyarakat. Lewat Akta ini juga pembangunan masjid atau surau dilarang tanpa persetujuan pemerintah. ${ }^{10}$

Selain itu, pemerintah juga mengggunakan Akta Keamanan Internal (ISA) sebagai senjata utama untuk menangkap mereka yang dituduh mengancam stabilitas dan keamanan bangsa. Lebih jauh, pemerintah meningkatkan pemantauan atas gerakan-gerakan yang dianggap berpotensi mengacaukan stabilitas rezim. Pada 1981, pemerintah menengarai terdapat kurang lebih 40 gerakan dakwah di Malaysia. Salah satunya adalah Ahmadiyah yang berpusat di Pakistan, yang dilarang pemerintah dan sejak 1982 status kemelayuan para anggotanya dilucuti. Demikian juga sejumlah sekte tarekat, seperti Qadiani dan Muhammadiyah Tariqah, dilarang. ${ }^{11}$ Pada 1985, Divisi

\footnotetext{
${ }^{10}$ Mutalib, Islam dan Etnisitas, h. 219.

${ }^{11}$ Choirie, Islam dan Nasionalisme, h. 199.
}

Urusan Agama di kantor Perdana Menteri (disebut dengan Pusat Islam) mengumumkan rencana pemerintah untuk memperluas unit Akidah dan Ajaran Sesat di bawah Pusat Penyelidikan Islam untuk menyaring rnasuknya ajaran--ajaran ekstremmilitan di Malaysia. Pada 1996, otoritas yang sama mengidentifikasi keberadaan 47 kelompok penyimpang, $14 \mathrm{di}$ antaranya dikatakan aktif dan melibatkan 1.000 orang pengikut. ${ }^{12}$

Tak lama setelah meletus insiden Memali 1985 yang menewaskan Ibrahim Libya $^{13}$, pemerintah menerbitkan kertas putih yang mengungkap mengenai ancaman ekstremisme agama di Malaysia. Di dalam kertas putih itu, diungkapkan adanya upaya--upaya oleh kelompok ekstremis yang hendak mendirikan negara Islam dengan cara kekerasan. Kelompok ini ditengarai menghasut kaum Melayu Muslim untuk membenci pemerintah dan berusaha menggulingkan pemerintahan multirasial serta menggantikannya dengan negara teokratis. ${ }^{14}$

Contoh tindakan represif pemerintah lainnya adalah pembubaran Darul Arqam pada 1994 karena diduga kelompok menyimpang, bahkan pemimpinnya, Ashaari, mengklaim diri

${ }^{12}$ Choirie, Islam dan Nasionalisme, h. 199-200.

${ }^{13}$ Nama sesungguhnya adalah Ibrahim Mahmud, dikenal dengan Ibrahim Libya. Diduga keras oleh pemerintah PAS mendukung Ibrahim Libya. Dalam insiden ini, 14 warga sipil, termasuk Ibrahim Libya, dan 4 polisi terbunuh. Lihat Milne dan Mauzy, Malaysian Politics, h. 87; lihat pula Mutalib, Islam dan Etnisitas, h. 218; Khoo Boo Teik, Paradoxes of Mahathirism An Intellectual Biography of Mahathir Mohamad (Selangor Darul Ehsan: Oxford University Press, 2001), h. 227-228.

${ }^{14}$ Government of Malaysia, White Paper on .Religious Extremism in Malaysia (Kuala Lumpur: Minister of Home Affairs, 1986). 
sebagai seorang nabi. ${ }^{15}$ Setahun kemudian, dengan menggunakan ISA ${ }^{16}$ pemerintah menangkap beberapa pemimpin dan pengikutnya karena dianggap mengancam keselamatan negara. Tindakan berikutnya yang diambil pemerintah Mahathir adalah mengumumkan akan menganggarkan RM 40 juta untuk membina dua buah Pusat Pemulihan Islam di bawah Rancangan Malaysia Ketujuh. ${ }^{17}$ Hal ini dilakukan karena ada dugaan dari pihak pemerintah, sebagaimana dinyatakan Menteri Hal -Ehwal Islam di Jabatan Perdana Menteri, bahwa jumlah orang murtad dan penyeleweng agama bertambah dalam tahun-tahun terakhir. Setahun sebelumnya, pemerintah menolak pemberlakukan hukum hudud di negara bagian Kelantan yang diperintah PAS. Mahathir menyatakan bahwa undang-undang Malaysia sudah sesuai dengan Islam, dan dia menegaskan kembali nilai-nilai pluralisme dan toleransi, serta memberikan peringatan terhadap bahaya ekstremisme agama. ${ }^{18}$

${ }^{15}$ Milne dan Mauzy, Malaysian Politics, h. 87; lihat pula Sivamurugan Pandian, Legasi Mahathir (Kuala Lumpur: Utusan Publications \& Distributors SDN BHD, 2005), h. 197.

${ }^{16}$ ISA adalah akta keselamatan dalam negeri yang bertujuan untuk menjaga kepentingan dan keselamatan dalam negeri. Akta ini memberi kekuasaan kepada pemerintah untuk menangkap dan menahan siapa saja yang diduga menimbulkan masalah keselamatan dalam negeri ... Lihat Nazaruddin $\mathrm{Hj}$. Moh Jali, Ma'rof Redzuan, Asnarulkhadi Abu Samah, Ismail Hj. Mohd Rashid, Pengajian Malaysia Kenegaraaan dan Kewarganegaraan (Petaling Jaya: Prentice Hall Pearson Malaysia Sdn. Bhd., 2004), h. 233.

${ }^{17}$ Sivamurugan Pandian, Legasi Mahathir (Kuala Lumpur: Utusan Publications \& Distributors SDN BHD, 2005), h. 198.

${ }^{18}$ M. B. Hooker, "Submission to Allah: The Kelantan Syariah Criminal Code (II), 1993". Dalam Virginia Hooker dan Norani Othman (eds.), Malaysia: Islam, Society and Politics (Singapore: ISEAS, 2003), h. 80-98.
ISA juga digunakan untuk menahan siapa saja yang mempromosikan fanatisme di kalangan orang Islam. Bahkan para ulama yang mendukung UMNO serta para fungsionaris Islam di tingkat Negara Bagian maupun Federal mengusulkan didirikannya 'Pusat Rehabilitas' bagi 'orang-orang Islam yang menyimpang'. Usulan ini diumumkan untuk pertama kalinya secara terbuka pada 1995. Usulan ini didukung banyak politisi dan anggota parlemen yang beragama Islam. Menurut JAKIM ${ }^{19}$, 'orang-orang yang menyimpang' adalah orang Islam yang kedapatan bersalah mengembangkan 'ajaran Islam yang sesat'. Kriteria dan gambaran -yang dibuat JAKIMtentang ajaran yang sesat ini dipandang

${ }^{19}$ JAKIM (Jabatan Kemajuan Islam Malaysia) merupakan perpanjangan tangan pemerintah. Lembaga ini digunakan untuk melakukan koordinasi dan mengatur institusi-institusi serta mengurus masalah-masalah keislaman. JAKIM memainkan beberapa fungsi: (1) bertanggungjawab sebagai perancang yang menentukan pembangunan dan kemajuan Islam di Malaysia; (2) merumuskan kebijakan untuk pembangunan Islam serta menjaga kesucian aqidah dan ajaran Islam; (3) membantu memformulasikan dan menyeragamkan undangundang dan peraturan yang diperlukan serta menilai dan melakukan koordinasi pelaksanaan undangundang dan administrasi yang sudah ada dari waktu ke waktu dalam rangka menyelesaikan permasalahan umat Islam; (4) melaksanakan program-program pembangunan umat dan penghayatan Islam dalam pemerintahan negara; (5) menyeragamkan mekanisme penetapan undang-undang serta peraturan-peraturan bagi administrasi keislaman di seluruh negara bagian; (6) membuat penilaian tentang program-program keislaman yang dilaksanakan di negara ini; (7) bertindak sebagai pengumpul, penyebar, dan pusat rujukan informasi mengenai Islam; (8) melaksanakan usaha-usaha pembangunan umat melalui kerjasama nasional maupun internasional. Lihat Helmiati, Islam dalam Politik Malaysia Studi Analisis Kebijakan "Pemerintahan UMNO" terhadap Islam pada Masa Pemerintahan Mahathir [1981-2003] (Disertasi Program Pasca Sarjana Universitas Islam Negeri Syarif Hidayatullah Jakarta, 2006), h. 140-141. 
sejumlah kalangan sangat kabur. Pada saat yang sama, mudah disalahgunakan untuk membungkam diskusi dan perdebatan publik tentang wacana hukum dan agama. ${ }^{20}$

Pada 17 April 1998, Berita Harian, melaporkan bahwa undang-undang kemurtadan sedang dirancang. Membaca laporan itu, Wakil Ketua ABIM saat itu mengusulkan agar JAKIM menyelenggarakan Konferensi Nasional membahas masalah itu, dan melibatkan badan-badan pemerintah yang lain, seperti Kementrian Pendidikan, Kementrian Penerangan dan Penyiaran, serta semua organisasi dakwah dan Islam yang terkait dengan masalah itu. Dan, pada 24 Mei 1998, Utusan Malaysia, melaporkan bahwa murtad sebagai pelanggaran Islam akan dikenai hukuman denda sebesar RM 5.000 (US\$1.000 lebih) atau kurungan tiga tahun, atau kedua-duanya. Sebelum laporan Utusan Malaysia itu, pada $23 \mathrm{Mei}$ 1998, Abdul Hamid Othrnan, Menteri pada Kantor (Urusan Islam) Perdana Menteri menegaskan bahwa Rancangan Undang--undang (RUU) kemurtadan sedang digodok dan diharapkan bisa disahkan di parlemen pada tahun berikutnya. RUU ini terutama akan memusatkan perhatian pada pengenalan 'cara-cara preventif' melawan pemurtadan, misalnya rehabilitasi. Di samping itu, juga akan menjelaskan ketetapan dalam Konstitusi Federal yang melarang umat non-Muslim menarik orang Islam masuk agama mereka. Zahid Hamidi, Ketua Pemuda UMNO, menyatakan dukungannya terhadap langkah-langkah pemerintah itu. Namun demikian, perkembangan RUU

${ }^{20}$ Choirie, Islam dan Nasionalisme, h. 201. ini terhambat oleh berbagai peristiwa yang menggemparkan selama periode Reformasi. $^{21}$

Ketika PAS muncul sebagai ancaman kuat bagi pemerintahan koalisi sejak Pemilu 1999, beredar pernyataan yang mengancam akan mengkriminalisasikan 'ekstremisme agama' PAS dengan menggunakan Seksyen 298 Kanun Keseksaan. Rais Yatirn, Menteri Undang-undang di Jabatan Perdana Menteri -sebagaimana dilaporkan The Star (24 November 2000) - sedang menimbang untuk menggunakan Kanun Keseksaan kepada siapa saja yang mengancam keamanan negara, termasuk mereka yang mengajarkan kesetiaan yang membabi buta dan kebencian terhadap pemimpin pemerintahan. Pada Juni 2001, Menteri Hal-Ehwal Islam, Abdul Hamid Zainal Abidin-seperti dilaporkan The Straits Times (9 Juni 2001)membeberkan adanya 17 kumpulan ajaran Islam sesat. Banyak di antara ajaran tersebut menentang pemerintah dan dianggap sebagai ancaman terhadap keamanan negara. ${ }^{22}$

Di samping itu, pemerintah juga melarang segala jurnal ataupun publikasi yang memuat materi-materi yang dianggap merugikan kepentingan nasional, termasuk artikel-artikel Islam yang mengkritik pemerintah. Oleh karena itu, pada 1983 jurnal dan terbitan yang kritis terhadap pemerintah, seperti Risalah (terbitan ABIM) dan Nadi Insan (jurnal kritik sosial), dilarang terbit. ${ }^{23}$ Pada 1999, ketua pengarah JAKIM (Jabatan Kemajuan Islam) di bawah

${ }^{21}$ Choirie, Islam dan Nasionalisme, h. 201-202.

${ }^{22}$ Choirie, Islam dan Nasionalisme, h. 202-203.

${ }^{23}$ Mutalib, Islam dan Etnisitas, h. 220. 
jabatan Perdana Menteri melaporkan bahwa Kementrian Dalam Negeri telah mengharamkan 195 buku dan risalah dalam bahasa Malaysia dan 80 buah dalam bahasa Inggris yang kandungannya bertentangan dengan ajaran Islam. Menurutnya, JAKIM telah mengungkap 94 jenis ajaran menyimpang yang disebarluaskan di seluruh negeri sejak awal publikasinya pada $1974 .^{24}$

Tuduhan terhadap radikalisme agama dan militansi Islam itu tampaknya terkait dengan keragaman mazhab intra-agama. Islam yang dianut sebagian besar Muslim Melayu adalah Islam Sunni dengan mazhab Syafi'i, sedangkan beberapa gerakan radikal dianggap beraliran atau setidak-tidaknya dipengaruhi ajaran-ajaran Islam syi'ah. Apalagi setelah revolusi Islam Iran, pemerintah Malaysia mencurigai gerakan-gerakan yang berusaha mengekspor revolusi yang sama di Malaysia. ${ }^{25}$ Sejak saat itu, setidaktidaknya setahun sekali pemerintah mengumumkan bahwa kerajaan sedang memantau dampak--dampak ajaran syi'ah yang menyimpang di negara Malaysia. Walaupun keislaman Syi'ah sepenuhnya diakui, pemerintah tetap saja melancarkan aksi menentang penyebaran kepercayaannya karena dinilai "tak sesuai" dengan konteks Malaysia. Itu sebabnya, dalam suatu kunjungannya ke Paris, Anwar Ibrahim menegaskan bahwa Malaysia tidak akan

\footnotetext{
${ }^{24}$ Choirie, Islam dan Nasionalisme, h. 203.

${ }^{25}$ Gerakan seperti ini diklaim oleh pemerintah menyukai cara kekerasan yang berencana menggulingkan kekuasaan dengan cara-cara nondemokratis. Tuduhan ini terkadang dialamatkan kepada PAS. Lihat Mutalib, Islam dan Etnisitas, h. 115-116.

${ }^{26}$ Choirie, Islam dan Nasionalisme, h. 203-204.
}

pernah menggunakan Iran sebagai studi kasus implementasi program-program Islamisasi pemerintahan. ${ }^{26}$

Sebagai antisipasi terhadap dampak revolusioner dari ajaran-ajaran militan syi'ah, Direktur Pusat Islam mengumumkan niat pemerintah untuk merancang mosi di parlemen guna mengamandemen Pasal (3) 1 Konstitusi Federal agar secara resmi mengakui Ahlus Sunnah Waljama'ah sebagai paham resmi Islam Malaysia dan melarang penyebaran aliran-aliran Islam lain. ${ }^{27}$

Kasus-kasus di atas tampaknya menunjukkan dilema Islamisasi pemerintahan Mahathir. Pada satu sisi, kekhawatiran terhadap potensi eksplosif politik Islam, dan dukungan resmi pemerintah terhadap pengembangan Islam pada sisi lain, dapat dibilang mencerminkan ketegangan dialektis hubungan agama dan negara. Namun, perlu dicatat, strategi pragmatis UMNO dengan mengusung identitas ganda (Islam-nasionalis) justru telah menempatkan partai ini pada posisi yang secara politis lebih diuntungkan daripada PAS. Sebaliknya, PAS yang sejak 1978 mengusung tema-tema universalisme Islam dan mengabaikan nasionalisme Melayu telah menjadi sasaran kecaman kaum Melayu. Penekanan PAS pada universalisme Islam ini pada akhirnya mendapat hukuman dari warga Melayu dengan kekalahan telaknya pada Pemilu 1986. Di samping itu, juga janji-janji PAS dalarn karnpanye untuk menghapuskan hak-hak istimewa bumiputera telah menuai kritik. Termasuk Anwar sendiri mengkritik PAS sebagai partai yang tak lagi bisa dipercaya karena ternyata disiapkan untuk mengkhianati warga

${ }^{27}$ Choirie, Islam dan Nasionalisme, h. 203-204. 
Melayu dengan berambisi membuang privelese dan hak-hak khusus mereka. ${ }^{28}$

Selain kasus-kasus tersebut, Choiri mengilustrasikan bahwa konflik internal UMNO yang menghasilkan dua faksi, Islam dan nasionalis pada 19871988, juga menggambarkan dilema lain politik Islamisasi UMNO dan pemerintah. Dilema politik UMNO ini terkait dengan tuduhan faksi nasionalis bahwa kubu yang dianggap sebagai faksi Islam itu justru tengah digoncang isu-isu korupsi dan skandal kekuasaan, yang dalam keseluruhan isi dan bentuknya bertentangan dengan Islam. ${ }^{29}$ Dalam kontes memperebutkan jabatan pimpinan partai pada 1987, faksi Islam tergabung dalam Tim A, diketuai Mahathir Mohamad. Di dalam faksi ini turut bergabung orang-orang seperti Ghafar Baba, 'pejabar' Deputi Perdana Menteri setelah Musa Hitam mengundurkan diri, dan Anwar Ibrahim, Menteri Pendidikan yang juga menjabat sebagai Ketua Pemuda UMNO. Sementara faksi nasionalis tergabung dalarn Tim B, dipirnpin Tengku Razaleigh. Turut bergabung dalam tim ini adalah mantan seteru utarnanya dalam perebutan Timbalan Presiden UMNO, Musa Hitam, dan Abdullah Badawi, Menteri Pertahanan dan Keamanan. ${ }^{30}$

Faksionalisasi tersebut perlu digarisbawahi, karena pernyataan Anwar Ibrahim dalam Straits Times (26

${ }^{28}$ Choirie, Islam dan Nasionalisme, h. 204.

${ }^{29} \mathrm{Hal}$ ini terkait dengan skandal BMF (Bumiputera Malaysia Finance), Maminco UMBC-Pernas melibatkan Daim Zainuddin-, orang kepercayaan Mahathir serta proyek Jembatan Pulau Pinang, Proton Saga, Daya Bumi, Perwaja, dan Lebuhraya UtaraSelatan yang diduga sarat dengan praktek kolusi dan nepotisme. Untuk penjelasan lebih lengkap lihat Teik, Paradoxes of Mahathirism, h. 209-224.

${ }^{30}$ Choirie, Islam dan Nasionalisme, h. 205; lihat pula Milne dan Mauzy, Malaysian Politics, h. 157.
April 1987) yang menyatakan bahwa kontes itu merefleksikan pertarungan antara kubu yang lebih menginginkan 'Islam' dan kubu yang lebih menghendaki 'nasionalisme Melayu' ${ }^{31}$ Kubu Mahathir digambarkan sebagai faksi yang menonjolkan Islam, sedangkan kubu Razaleigh digambarkan sebagai faksi yang lebih menginginkan nasionalisme Melayu. Pertarungan itu akhirnya dimenangkan faksi Mahathir yang mengungguli kubu nasionalis. Meskipun demikian, Mahathir menang dari Razaleigh dengan selisih suara tipis (761 lawan 718), sementara Ghafar Baba mengalahkan Musa Hitam dengan selisih suara yang juga tidak terlalu banyak (739 lawan 699). ${ }^{32}$

\section{Kebijakan Islamisasi Mahathir}

Era kepemimpinan Mahathir ditandai dengan minatnya yang lebih besar dan substantif dalam mengusung Islam dalam berbagai program dan kebijakan pemerintah. Di era kepemimpinannyalah, dukungan pemerintah terhadap Islam di Malaysia berlangsung lebih dari sekadar dukungan simbolis seperti pembangunan masjid--masjid, penyelanggaraan kompetisi hafalan alQur'an, dan perayaan upacara--upacara keislaman. Secara keseluruhan, perlindungan umum yang dilakukan pemerintah Mahathir terhadap upaya memajukan Islam di negara itu, menunjukkan bahwa Mahathir telah menjadi seorang pendukung Islam yang berani, dan juga seorang politisi yang sangat cerdik. ${ }^{33}$

${ }^{31}$ Choirie, Islam dan Nasionalisme, h. 205.

${ }^{32}$ Shamsul A.B., “The Battle Royal: 1987 UMNO Elections". Dalam M. Ayoob dan Ng Chee Yuen (eds.), Southeast Asian Affairs (Singapore: ISEAS, 1988), h. 170-88

${ }^{33}$ Mutalib, Islam dan Etnisitas, hal. 193. 
Kendatipun secara tradisional terlihat simbolis, di bawah pemerintahan Mahathir, perlakuan pemerintah terhadap agama memperoleh dimensi yang lebih substantif. Ini dapat dilihat dari perhatian pemerintah yang besar terhadap penelitian, perencanaan, dan pengadaan secara sistematis programprogram yang ditujukan untuk membekali rakyat Muslim dalam menghadapi kehidupan modern yang lebih kompleks. Dalam periode Mahathir, program Islamisasi pemerintah mulai dari menggunakan simbol-simbol dan retorika Islam hingga mendirikan lembaga-lembaga Islam ${ }^{34}$ (lihat tabel di bawah).

Dimulai ketika menduduki jabatan puncak sebagai Perdana Menteri dan Presiden UMNO di tahun 1981, Mahathir terus berupaya meyakinkan rakyat Malaysia lewat kebijakankebijakannya bahwa pemerintah dan UMNO benar-benar mendukung prinsip-prinsip Islam. ${ }^{35}$ Selama 20 tahun memerintah, Mahathir terus-menerus berupaya meyakinkan citra Islami pemerintah, berupaya memadukan Islam dan kemelayuan, serta mengasosiasikan Islam dengan pembangunan ekonomi. ${ }^{36}$

Tabel 2

Kebijakan Islamisasi Pemerintahan Mahathir, 1978-1988

\begin{tabular}{|c|c|c|}
\hline No & Tahun & Kebijakan \\
\hline 1. & 1978 & $\begin{array}{l}\text { Deklarasi pemerintah merevisi sistem hukum nasional agar } \\
\text { lebih selaras dengan Hukum Islam. }\end{array}$ \\
\hline 2. & 1979 & $\begin{array}{l}\text { Deklarasi pemerintah untuk mendirikan Pusat Penelitian } \\
\text { Islam Asia Tenggara, senilai M\$ } 26 \text { juta. }\end{array}$ \\
\hline 3. & 1979 & $\begin{array}{l}\text { Pengetahuan agama Islam ditetapkan sebagai materi ujian } \\
\text { di tingkat Sijil Pelajaran Malaysia. }\end{array}$ \\
\hline 4. & 1979 & Penetapan secara resmi Bulan Dakwah Nasional. \\
\hline 5. & 1980 & $\begin{array}{l}\text { Deklarasi politik untuk menyusun kembali model sistem } \\
\text { ekonomi Malaysia menjadi model Islam. }\end{array}$ \\
\hline 6. & 1980 & $\begin{array}{l}\text { Pembangunan untuk pertama kali Sekolah Guru Islam yang } \\
\text { menghabiskan biaya } M \$ 22 \text { juta. }\end{array}$ \\
\hline 7. & 1981-82 & $\begin{array}{l}\text { Pendirian Bank Islam, Pegadaian Islam, Asuransi Islam, } \\
\text { Yayasan Ekonomi Islam, dan pembentukan Kelompok } \\
\text { Sumber daya Islam serta Kelompok Khusus Penegakan } \\
\text { Islam. }\end{array}$ \\
\hline 8. & 1981 & $\begin{array}{l}\text { Kenaikan yang mencolok jumlah program-program } \\
\text { keislaman di dalam siaran radion dan televisi. }\end{array}$ \\
\hline 9. & 1982 & $\begin{array}{l}\text { Pengadaan tempat yang permanen untuk Kamp Training } \\
\text { Islam Internasional. }\end{array}$ \\
\hline 10. & 1982 & Anwar Ibrahim bergabung dengan UMNO dan pemerintah. \\
\hline
\end{tabular}

${ }^{34}$ Choirie, Islam dan Nasionalisme, h. 187.

${ }^{35}$ Mutalib, Islam dan Etnisitas, hal. 193.

${ }^{36}$ Patricia Martinez, "Mahathir, Islam, dan Dilema
Melayu Baru". Dalam Ho Khai Leong dan James Chin (ads.), Pentadbiran Mahathir : Prestasi dan Krisis dalam Pemerintahan (Singapore \& Kuala Lumpur: Times Books International, 2003), hal. 269. 
Di dalam kebijakan luar negeri, dengan naiknya Mahathir sebagai Perdana Menteri, seluruh spektrum keterlibatan Malaysia di dunia internasional mulai ditata kembali. Salah satu perubahan pentingnya adalah perhatiannya atau keberpihakannya terhadap dunia Muslim. ${ }^{37}$ Untuk itu, membentuk Tabung Rakyat Palestina. ${ }^{39}$ Keberpihakan Malaysia terhadap dunia Muslim juga ditunjukkan dengan menempatkan dirinya sebagai salah satu aktivis yang mengidentikkan dirinya dengan persoalan-persoalan dunia Islam. ${ }^{40}$ Sikap dukungan terhadap perjuangan PLO dan Palestina

\begin{tabular}{|c|c|}
\hline 11. & 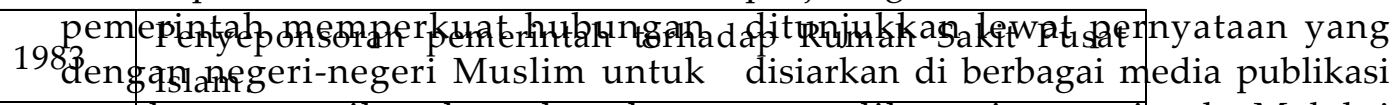 \\
\hline 12. & 983endrementstrasik \\
\hline 13. & 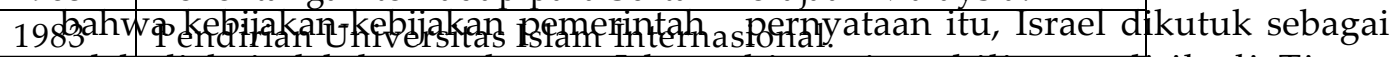 \\
\hline 14. & 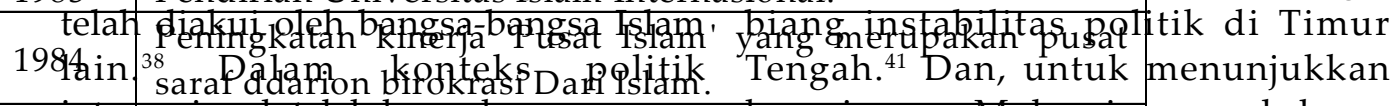 \\
\hline 15. & 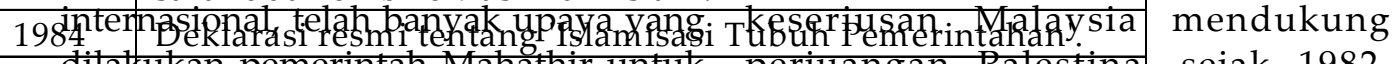 \\
\hline 16. & 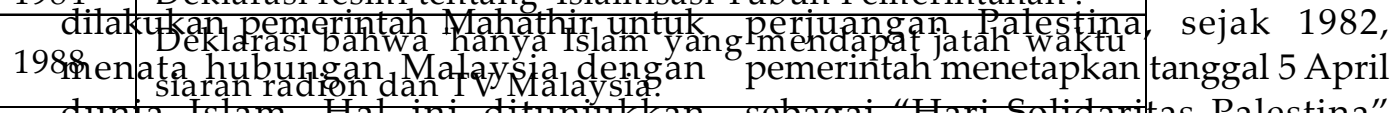 \\
\hline 17. & 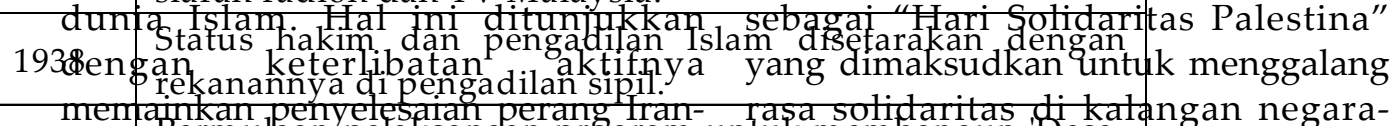 \\
\hline 18. & 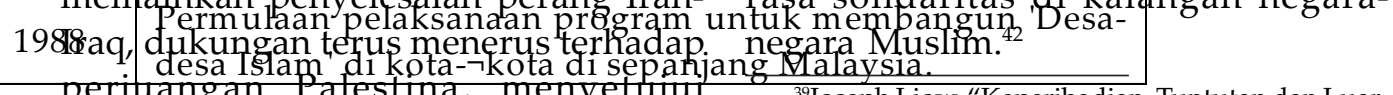 \\
\hline & 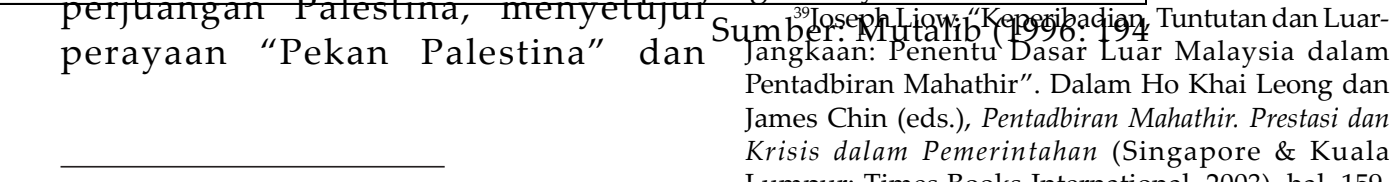 \\
\hline & 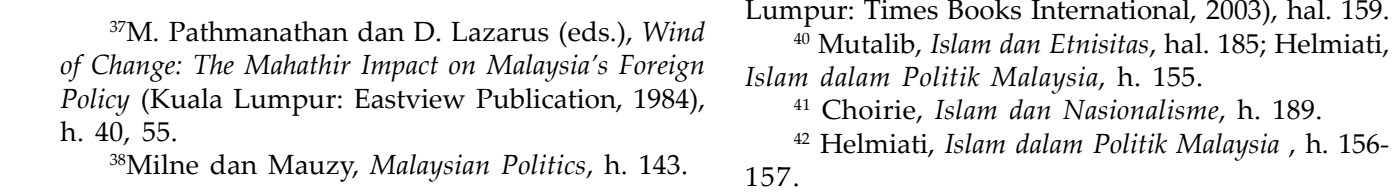 \\
\hline
\end{tabular}


Dimulai sejak 1981, pemerintah terlibat aktif dalam mensponsori konferensi-konferensi internasional, seminar dan eksposisi tahunan, yang menyoroti isu dan problem-problem di dunia Islam. Topik-topik yang dikupas menggarisbawahi agenda-agenda pemerintah. Pada dekade pertama pemerintahan Mahathir, Kuala Lumpur telah menjadi tuan rumah bagi berbagai konferensi Islam internasional yang diselenggarakan hampir setiap tahun. Konferensi-konferensi tersebut menyoroti berbagai isu seperti pendekatan Islam terhadap Pembangunan Teknologi (1983), Peradaban Islam (1984), Pemikiran Islam (1984), Simposium Islam Internasional (1986), Manajemen Islam Kawasan AsiaPasifik (1987), Ekonomi Islam (1987), Media Islam dan Dunia Modern (1987), serta Islam dan Filsafat Islam (1989). ${ }^{43}$

Keterlibatan Mahathir dalam program pembangunan Islam sesungguhnya telah dimulai ketika ia kembali ke panggung utama politik Malaysia. ${ }^{44}$ Begitu ditunjuk sebagai Menteri Pendidikan pada 1974, dan menemukan bahwa sistem pengajaran Islam tidak efektif dan kurang relevan dengan konteks Malaysia, Mahathir segera mengadakan pengkajian kembali pendidikan keagamaan Islam untuk merombak sistem pengajaran Islam yang ada. Kemudian dibentuklah Dewan Penasehat untuk Pendidikan Islam yang bertujuan agar Islam diajarkan dalam cara yang sesuai dengan kebutuhan modernisasi warga Muslim Melayu. Tindakan yang menjadi simbol paling nyata pemihakan atas

${ }^{43}$ Shanti Nair, Islam in Malaysian Foreign Policy (Singapore: ISEAS, 1996), hal. 115.

${ }_{44}$ Choirie, Islam dan Nasionalisme, h. 190.
Islam adalah dibentuknya Pusat Islam Nasional pada 1974, sebuah pusat yang berfungsi untuk mengkoordinasi seluruh kegiatan Islam di Malaysia. ${ }^{45}$

Pada tahun yang sama, Mahathir juga menyerukan kepada para intelektual Muslim di negaranya untuk membantu mengislamisasi pengajaran ilmu pengetahuan alam di sekolahsekolah. Kementrian Mahathir juga memberlakukan sistem standarisasi buku teks Islam terhadap keseluruhan tingkat pendidikan, hingga tingkat pendidikan tinggi. Pada tahun berikutnya, Kementrian Pendidikan juga menyetujui pengalokasian anggaran senilai $\mathrm{M} \$ 22$ juta untuk memperbaiki pelaksanaan pelatihan guru Islam dan untuk membentuk Yayasan Dakwah Islamiah. Pada tahun 1977, terutama sebagai tanggapan atas PAS, pemerintah menginstruksikan seluruh pegawai perempuannya untuk berpakaian sopan. ${ }^{46}$

Di dalam Rencana Malaysia Ketiga dan Keempat untuk periode pemerintahan 1976-1981 dan 1981-1986, pemerintah semakin menunjukkan kesungguhannya dalam menyambut penegasan kembali Islam. Di dalam Rencana Ketiga, misalnya, klausul ‘Islam tetap menjadi sumber kekuatan bagi bangsa Malaysia' telah diwujudkan secara nyata dalam peningkatan anggaran pemerintah dan dukungan moral pemerintah dalam bidang pengajaran Islam di sekolah-sekolah, dan juga dalam pembangunan masjidmasjid serta berbagai institusi Islam. ${ }^{47}$

\footnotetext{
${ }^{45}$ Mutalib, Islam dan Etnisitas, hal. 195; Helmiati, Islam dalam Politik Malaysia, h. 145-146.

${ }^{46}$ Mutalib, Islam dan Etnisitas, hal. 195-196; Helmiati, Islam dalam Politik Malaysia, h. 46.

${ }^{47}$ Mutalib, Islam dan Etnisitas, hal. 199; Helmiati, Islam dalam Politik Malaysia, h. 146-147.
} 
Pada tahun 1980, di bidang pendidikan, pemerintah mendirikan Maktab Perguruan Islam (Islamic Teachers's College) yang menghabiskan biaya MS 22 juta. Dari Maktab ini murid-murid yang berbakat akan dikirim ke Mesir, Pakistan, dan Indonesia untuk melanjutkan studi. Setahun sebelumnya, 1979, melalui Kabinet Panitia Pengkajian Kurikulum Sekolah yang diketuai Mahathir pemerintah memutuskan untuk menjadikan pengetahuan agama Islam sebagai bahan ujian pada tingkat sijil pelajaran Malaysia dan studi-studi tentang agama dan moral (seperti peradaban Islam) ditetapkan sebagai pelajaran wajib bagi semua murid. Dalam berbagai kesempatan, Mahathir mengungkapkan pernyataan yang selalu diulang-ulang sepanjang tahun 1980 bahwa pembangunan ekonomi tidak bisa dilaksanakan dengan mengorbankan kemajuan spiritual. ${ }^{48}$

Dalam posisinya sebagai Perdana Menteri, Mahathir semakin leluasa mempromosikan Islam. Dalam Perhimpunan Agung UMNO ke-38 pada September 1982, Mahathir menegaskan komitmen pemerintah terhadap pelaksanaan nilai-nilai Islam di Malaysia. Bahkan Mahathir menyatakan bahwa masalah besar yang kita hadapi adalah berjuang mengubah sikap kaum Melayu agar sesuai dengan tuntutan--tuntutan Islam di abad modern. Untuk itu, tugas UMNO adalah meningkatkan amaliah Islam dan memastikan bahwa komunitas Melayu benar-benar mengikuti ajaran Islam. Dan, pada tahun 1984, Mahathir secara

${ }^{48}$ Mutalib, Islam dan Etnisitas, hal. 199-200; Helmiati, Islam dalam Politik Malaysia, h. 146. resmi mengumumkan niatnya untuk "mengislamkan jentera kerajaan". ${ }^{49}$

Dalam upaya memperjelas wajah Islamisasi pendidikan, pada tahun 1982 Mahathir menerima rekomendasi untuk mendirikan Universitas Islam Antarbangsa. Universitas ini dibangun guna menghasilkan para profesional Muslim yang berkualitas di seluruh bidang pengetahuan. ${ }^{50}$ Satu tahun sebelumnya, Mahathir mensponsori upaya pengkajian terhadap berbagai segi mengenai sistem ekonomi Islam untuk memastikan bahwa proyek-proyek pembangunan pemerintah tidak bertentangan dengan prinsip-prinsip Islam. $^{51}$

Langkah tersebut diawali dengan pembaruan sistem ekonomi yang disesuaikan dengan ajaran-ajaran Islam, meliputi prinsip 'tidak ada bunga' di dalam setiap transaksi keuangan. Gambaran mengenai penegakan citacita ekonomi Islam dituangkan dalam pendirian Bank Islam pada 1982 dengan modal sendiri M\$ 100 juta dan modal pinjaman M\$ 500 juta. Bank Islam yang beroperasi tanpa memberlakukan bunga digambarkan oleh Menteri Keuangan sebagai 'langkah pertama' usaha pemerintah untuk menumbuhkan secara perlahan nilai-nilai Islam dalam sistem ekonomi dan keuangan negara menggantikan sistem ekonomi yang berdasarkan Barat yang diberlakukan sekarang. ${ }^{52}$

Demikian pula di bidang hukum dan perundang-undangan, pemerintah

${ }^{49}$ Choirie, Islam dan Nasionalisme, h. 192.

${ }^{50}$ Helmiati, Islam dalam Politik Malaysia, h. 147; Choirie, Islam dan Nasionalisme, h. 92.

${ }^{51}$ Mutalib, Islam dan Etnisitas, hal. 200-201.

${ }^{52}$ Mutalib, Islam dan Etnisitas, hal. 201-2002; Helmiati, Islam dalam Politik Malaysia, h. 148; lihat pula Milne dan Mauzy, Malaysian Politics, h. 85. 
selama dekade 1980-an dan 1990-an mengeluarkan banyak hukum Islam atau mengarnandemen hukum yang ada untuk semakin banyak menyerap aspek-aspek Islam. Hukum-hukum syariat tentang kejahatan dikeluarkan untuk menjamin bahwa gaya hidup kaum Muslim tidak melanggar ajaranajaran Islam. Tindak--tindak kejahatan baru diciptakan dan pengawasan moral serta pelaksanaan dan pemberlakukan hukum bagi orang-orang Islam diperkenalkan. Makan di ternpat umum selarna bulan Ramadhan, mengonsumsi minuman-minuman beralkohol di tempat umum, perempuan atau laki-laki yang asyik tukar menukar model pakaian, homoseksualitas dan lesbianisme merupakan tindakantindakan kejahatan yang dapat dihukum menurut syariah. ${ }^{53}$

Untuk menjustifikasi berbagai inisiatif gerakan keislamannya, pemerintahan Mahathir semakin banyak merujukkan semua gerakannya pada sejarah Islam dan peran Islam dalam peradaban manusia masa silam. Dalam konteks inilah, pada tahun 1982, pemerintah menetapkan studi tentang budaya dan peradaban Islam sebagai pelajaran wajib di sekolah dan universitas. ${ }^{54}$

Tampaknya program Islamisasi pemerintah telah memikat banyak orang. Salah satunya adalah Anwar Ibrahim, Presiden ABIM saat itu. Anwar yang pernah berkampanye untuk PAS

${ }^{53}$ Choirie, Islam dan Nasionalisme, h. 193; lihat pula Zainah Anwar, "Berebut Paling Saleh: Islam dan Politik di Malaysia". Dalam Ulil Abshar-Abdalla (ed.), Islam dan Barat: Demokrasi dalam Masyarakat Islam (Jakarta: Friedrich-Naumann Stiftung (FNS),Indonesia dan Pusat Studi Islam Paramadina, 2002), hal. 85.

${ }^{54}$ Choirie, Islam dan Nasionalisme, h. 193-194. pada pemilu 1978 ternyata berhasil dibujuk untuk bergabung dengan UMNO dan pemerintahan serta menjadi kandidat UMNO dalam pemilu 1982. Disinyalir ada tiga syarat yang diajukan Mahathir kepada Anwar untuk dapat bergabung dengan UMNO. Pertama, ABIM mencabut seluruh asosiasinya dengan PAS, termasuk menggunakan tiket PAS untuk bertarung dalam pemilu. Kedua, mencabut pernyataan bahwa NEP (New Economic Policy)tidak Islami dan mendukung promosi hakhak Bumiputera. Ketiga, tidak mengecam kebijakan pendidikan Melayu..$^{55}$

Dengan masuknya Anwar ke jajaran koalisi yang berkuasa itu, menjadikan pemerintahan Mahathir semakin aktif melaksanakan berbagai kebijakan Islamisasi, termasuk di antaranya amandemen konsitusi yang krusial, yang pertama kali diusulkan pada 1986 dan kemudian diwujudkan dalam amandemen 1988 di bawah Pasal 121 (1A) Konstitusi Federal. Amandemen ini membagi wilayah yurisdiksi Pengadilan Sipil dan Syari'at, yang secara substansial lebih condong pada Pengadilan Syari'at. ${ }^{56}$

Sejumlah lembaga didirikan dan diberi kekuasaan untuk lebih jauh mengislamkan hukum dan masyarakat. Pusat Islam didirikan sebagai badan pemerintah federal dan dikembangkan dari the Islamic Affairs Division of Prime Minister's Department (Bagian Urusan

55 John Hilley, Malaysia: Mahathirism, Hegemony and the New Opposition (London \& New York: Zed Books, 2001), hal. 94.

${ }^{56}$ Norani Othman, "Islamisasi dan Demokratisasi di Malaysia dalam Konteks Regional dan Global". Dalam Ariel Heryanto dan Sumit K. Mandal (eds.), Menggugat Otoriterisme di Asia Tenggara: Perbandiugan dan Pertautan antara Indonesia dan Malaysia (Jakarta: Kepustakaan Populer Gramedia, 2004), hal. 246-47. 
Islam Kantor Perdana Menteri). Pada 1996, ditingkatkan menjadi JAKIM (Jabatan Kemajuan Islam Malaysia). Lembaga-lembaga utama lain yang didirikan oleh pemerintah Federal antara lain YADIM (Yayasan Islam Malaysia), IKIM (Institut Kefahaman Islam Malaysia), dan ITU (the International Islamic University-Universitas Islam Antarbangsa). ${ }^{57}$

Bergabungnya Anwar tersebut tampaknya membuat Islam menjadi faktor amat penting dalam identitas politik UMNO dan kaum Melayu. Anwar dipandang banyak pihak memiliki pengaruh penting dalam kebijakan-kebijakan Islamisasi pemerintah. Bahkan Anwar Ibrahim memiliki peran penting dalam pendirian Bank Islam dan Universitas Islam Antarbangsa. Dalam kurun waktu 1983-1984, Anwar telah menjadi pembuka jalan bagi terciptanya kebijakan-kebijakan Islam dalam pemerintahan. ${ }^{58}$

Untuk beberapa kebijakan Islam lainnya, bukannya Mahathir sendiri, melainkan justru Anwar-lah yang diharuskan menyampaikannya. Kebijakan-kebijakan itu meliputi pembangunan tempat permanen untuk Kamp Pemuda Islam Internasional pada September 1982, relokasi klub-klub Turf jauh dari pusat kota, keputusan untuk menolak pembukaan rumah judi baru, pendirian Pegadaian Islam, Asuransi Islam (Syarikat TakafuI), dan melarang warga Muslim menjadi pelanggan Casino Genting Highlands, satu-satunya kasino di negara itu. ${ }^{59}$ Sejak 1982, Mahathir bersama Anwar mendorong proses Islamisasi internal UMNO yang diwujudkan dengan banyaknya seminar dan pelatihan-pelatihan keislaman yang diselenggarakan di seluruh jenjang pengkaderan partai. ${ }^{60}$
${ }^{58}$ Judith Nagata, The Reflowerins of Malaysian Islam: Modern Religious Radicals and Their Roots (Vancouver: University of British Columbia Press, 1984), hal. 159.

${ }^{59}$ Mutalib, Islam dan Etnisitas, hal. 205.

${ }^{60}$ Choirie, Islam dan Nasionalisme, h. 195. 